\title{
Fertilizing capacity of the cryptorchid rat
}

\author{
H. Hayashi and A. P. Cedenho \\ Laboratory of Embryology, Department of Morphology, Escola Paulista de Medicina, \\ Rua Botucatu 720, São Paulo, Brazil 04023
}

\begin{abstract}
Summary. Rats were surgically made bilaterally cryptorchid and after 4-8 days the testes were returned to the scrotum. After 70 days fertility was tested by pairing with females. Fertility was restored in $5 / 6$ rats with testes cryptorchid for 4 or 5 days, but only $2 / 9$ were fertile when the duration of cryptorchidism was $6-8$ days. The sterility was due to irreversible degeneration of the spermatogonial stem cells. The testes of infertile males were smaller and lighter than those of fertile males and the seminiferous tubule diameters were reduced.
\end{abstract}

\section{Introduction}

The damage produced in the seminiferous tubules of testes retained in the abdomen is well established (Sniffen, 1952; Sohval, 1954; Clegg, 1961; Cummins \& Glover, 1970; Hayashi \& Harrison, 1971; Chowdhury \& Steinberger, 1972; Hadziselimović, 1977; Jones, Anderson, Fang, Landau \& Rosenfield, 1977; van Straaten \& Wensing, 1977), but it is not certain how long the period of retention in the abdominal cavity has to be for irreversible damage to occur. We have therefore investigated the minimum period which the germinal epithelium in cryptorchid rats can tolerate without loss of fertilizing capacity.

\section{Materials and Methods}

Groups of albino rats of 90-100 days of age weighing 245-315 g were surgically made bilaterally cryptorchid. Both testes were then returned to the scrotum on Days 4, 5, 6, 7 and 8 ( 3 rats/group) after the first operation because degeneration of the seminiferous tubules had previously been observed to occur in testes which had been retained for more than 6 days. Cryptorchidism was effected through a midline abdominal incision under ether anaesthesia. The testes were attached to the dorsolateral abdominal musculature by a stitch through the gubernaculum testis. Orchiopexy was performed through the same incision by separating the gubernaculum testis from the abdominal musculature and replacing the testis in the scrotum.

After orchiopexy, these rats and those of the control (untreated) and sham-operated (both operations) groups were kept individually in cages for 70 days. Every animal was then paired with a female rat of 90-100 days of age, weighing approximately $280 \mathrm{~g}$, for 30 consecutive days. The cages were checked daily for the birth of litters. After killing the rats, the testes were measured and weighed before fixation in Bouin's fluid for $24 \mathrm{~h}$, embedding in paraffin wax, sectioning at $6 \mu \mathrm{m}$ and staining with haematoxylin and eosin for histological observations.

The mean diameter of the seminiferous tubules was calculated by measuring 20 transversely sectioned tubules, chosen at random in each testis, with a micrometer eyepiece at $\times 80$ magnification. 


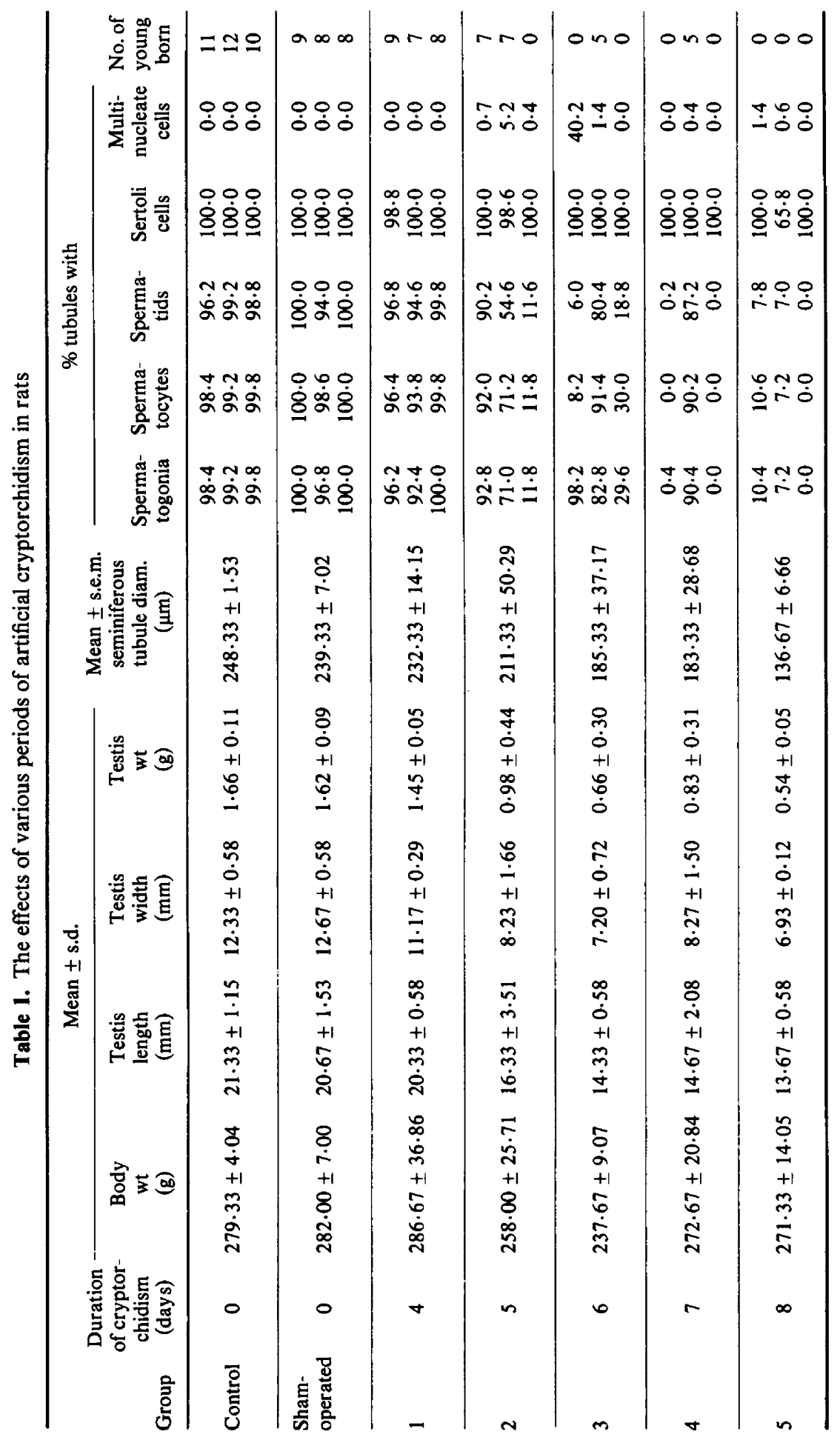


The percentages of the seminiferous tubules with particular cell types were calculated by counting 500 transversely sectioned tubules chosen at random in each testis at $\times 400$ magnification. The cell types identified were: (1) spermatogonia types A, intermediate and B (Leblond \& Clermont, 1952); (2) spermatocytes, which consisted of early and late primary spermatocytes (Clegg, 1963) or the resting, leptotene, zygotene, transitional and true pachytene types of cell described by Leblond \& Clermont (1952); and (3) spermatids which included the Golgi, cap, acrosome and maturation phases described by Leblond \& Clermont (1952).

\section{Results}

The results are shown in Table 1.

\section{Fertile animals}

Only 7 of the temporarily cryptorchid rats sired young. The testes of all except one of the animals of Groups 1 and 2 were similar to those of normal rats, although some of the testes were slightly smaller in size and weight and there was a reduced diameter and disorganization of mature phase spermatids in some seminiferous tubules. Multinucleate cells were seen in the Group 2 testes (Table 1). The testes of the 2 fertile animals in Groups 3 and 4 were not as reduced in size and weight as were those of the others in the groups, although the values were lower than those in Groups 1 and 2 and in the control and sham-operated animals. There was an increasing number of tubules showing a disorganized epithelium lacking in spermatids. Some tubules had a total absence of spermatogonial stem cells and possessed only Sertoli cells.

\section{Infertile animals}

The testes in all these rats were much reduced in size and weight (Table 1). In the Group 2 animal almost all the seminiferous tubules contained only Sertoli cells and the proportion of interstitial tissue appeared to be increased. A very small number of tubules still contained spermatogonia at various stages of differentiation. In Group 3, some of the seminiferous tubules displayed only primary spermatocytes with a large number of multinucleate cells, but most contained a few irregularly arranged Sertoli cells. In Groups 4 and 5 the seminiferous tubules were shrunken with only a few multinucleate cells and sparse Sertoli cells whose nuclear chromatin was condensed. A strongly basophilic amorphous substance was seen in some tubular lumina.

\section{Discussion}

One of the first effects of cryptorchidism on spermatogenesis is an interference with spermiogenesis. Spermatids that cannot mature either coalesce or undergo karyokinesis without subsequent cytokinesis and form multinucleate cells which appear within $24 \mathrm{~h}$ and become prominent in the lumen of all seminiferous tubules at 5 days (Hayashi \& Harrison, 1971; Kaya \& Harrison, 1975; Harrison, 1978). In testes which have been cryptorchid for 1 day, there is a breakdown of the microtubular system of spermatids by depolymerization and a disorganization of their chromatin (Jones et al., 1977). Whether the depolymerization is due to an increase in temperature or to some other factor is not clear. However, as stated by Lee \& Fritz (1972), this arrest of spermatid maturation is probably due to the release of hydrolytic enzymes from thermally sensitive lysosomes because of the adverse abdominal temperature. 
In this investigation, regeneration or degeneration of the seminiferous tubules occurred according to the time that had elapsed between artificial cryptorchidism and orchiopexy.

A period of artificial cryptorchidism greater than 5-7 days produces irreversible sterility although variation in individual response is seen. All seminiferous tubules suffer damage to a variable degree during the initial days of cryptorchidism but, after orchiopexy, spermatogenesis can be re-established over a period of 70 days in those tubules in which type A spermatogonia were not affected at the end of the period of cryptorchidism.

The critical time of 5-7 days cryptorchidism has been confirmed by light and electron microscopy in adult rats (Jones et al., 1977), and by Cummins \& Glover (1970) who demonstrated sterility in cryptorchid rabbits within 7 days.

In the present work the mean diameter of seminiferous tubules as well as the percentages of cell types of the seminiferous epithelium became less as the duration of cryptorchidism increased and the difference between fertile and infertile animals is clearly shown (Table 1).

We are indebted to the Research Aid Fellowship of São Paulo State (FAPESP) Brazil who provided the financial support for this research. We thank Mr E. R. Paiva and Mr H. F. Novo, Sub-department of Biostatistics, for their assistance with the statistics.

\section{References}

Chowdhury, A.K. \& Steinberger, E. (1972) The influence of cryptorchid milieu on the initiation of spermatogenesis in the rat. J. Reprod. Fert. 29, 173-178.

Clegg, E.J. (1961) Further studies on artificial cryptorchidism: quantitative changes in the interstitial cells of the rat testis. J. Endocr. 21, 433-441.

Clegg, E.J. (1963) Studies on artificial cryptorchidism: degenerative and regenerative changes in germinal epithelium of the rat testis. J. Endocr. 27, 241-251.

Cummins, J.M. \& Glover, T.D. (1970) Artificial cryptorchidism and fertility in the rabbit. J. Reprod. Fert. 23, 423-433.

Hadziselimović, F. (1977) Cryptorchidism. Adv. Anat. Embryol. Cell. Biol. 53, 1-71.

Harrison, R.G. (1978) Clinical Embryology. Academic Press, London.

Hayashi, H. \& Harrison, R.G. (1971) The development of the interstitial tissue of the human testis. Fert. Steril. 22, 351-355.
Jones, T.M., Anderson, W., Fang, V.S., Landau, R.L. \& Rosenfield, R.L. (1977) Experimental cryptorchidism in adult male rats: Histological and hormonal sequelae. Anat. Rec. 189, 1-27.

Kaya, M. \& Harrison, R.G. (1975) An analysis of ischaemia on testicular ultrastructure. J. Path. 117, 105-117.

Leblond, C.P. \& Clermont, Y. (1952) Definition of the stages of the cycle of the seminiferous epithelium in the rat. Ann. N.Y.Acad. Sci. 54, 548-573.

Lee, L.P.K. \& Fritz, I.B. (1972) Studies on spermatogenesis in rats. J. biol. Chem. 247, 7956-7961.

Sniffen, R.C. (1952) Histology of normal and abnormal testis at puberty. Ann. N.Y. Acad. Sci. 55, 609-618.

Sohval, A.R. (1954) Histopathology of cryptorchidism. Am. J. Med. 16, 346-362.

van Straaten, H.W.M. \& Wensing, C.J.G. (1977) Histomorphometric aspect of testicular morphogenesis in the naturally unilateral cryptorchid pig. Biol. Reprod. 17, 467-472. 